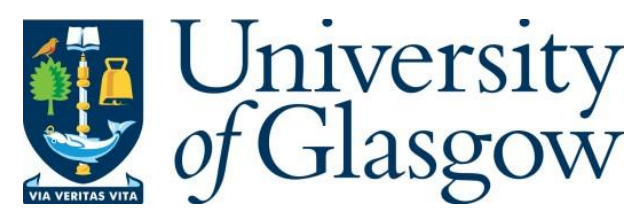

Karlõševa, A., Nõmmann, S., Nõmmann, T., Urbel-Piirsalu, E., Budziński, W.,

Czajkowski, M. and Hanley, N. (2016) Marine trade-offs: comparing the benefits of offshore wind farms and marine protected areas. Energy Economics, 55, pp. 127-134.

There may be differences between this version and the published version. You are advised to consult the publisher's version if you wish to cite from it.

http://eprints.gla.ac.uk/154106/

Deposited on: 20 December 2017

Enlighten - Research publications by members of the University of Glasgow http://eprints.gla.ac.uk 


\section{Accepted Manuscript}

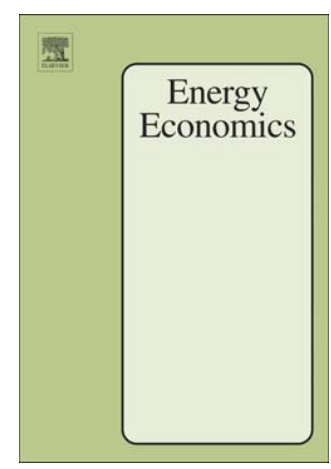

Marine trade-offs: Comparing the benefits of off-shore wind farms and marine protected areas

Aljona Karlõševa, Sulev Nõmmann, Tea Nõmmann, Evelin Urbel-Piirsalu, Wiktor Budziński, Mikołaj Czajkowski, Nick Hanley

PII:

S0140-9883(16)00032-3

DOI: $\quad$ doi: $10.1016 /$ j.eneco.2015.12.022

Reference: $\quad$ ENEECO 3245

To appear in: $\quad$ Energy Economics

Received date: 24 July 2015

Revised date: $\quad 10$ November 2015

Accepted date: 27 December 2015

Please cite this article as: Karlõševa, Aljona, Nõmmann, Sulev, Nõmmann, Tea, UrbelPiirsalu, Evelin, Budziński, Wiktor, Czajkowski, Mikołaj, Hanley, Nick, Marine tradeoffs: Comparing the benefits of off-shore wind farms and marine protected areas, Energy Economics (2016), doi: 10.1016/j.eneco.2015.12.022

This is a PDF file of an unedited manuscript that has been accepted for publication. As a service to our customers we are providing this early version of the manuscript. The manuscript will undergo copyediting, typesetting, and review of the resulting proof before it is published in its final form. Please note that during the production process errors may be discovered which could affect the content, and all legal disclaimers that apply to the journal pertain. 


\title{
Marine trade-offs: comparing the benefits of off-shore wind farms and marine protected areas
}

\author{
Aljona Karlõševa ${ }^{1, *}$, Sulev Nõmmann ${ }^{1}$, Tea Nõmmann ${ }^{1}$, Evelin Urbel-Piirsalu ${ }^{1}$, \\ Wiktor Budziński ${ }^{2}$, Mikolaj Czajkowski ${ }^{2}$, Nick Hanley ${ }^{3}$
}

\begin{abstract}
:
The drive to increase renewable electricity production in many parts of Europe has led to an increasing concentration of new wind energy sites at sea. This results in a range of environmental impacts which should be taken into account in a benefit-cost analysis of such proposals. In this paper, we use choice modelling to investigate the relative gains and losses from siting new windfarms off the coast of Estonia, relative to the option of creating a new marine protected area. We find that, while respondents are generally opposed to converting marine shoals to conventional wind farms and prefer the establishment of marine protected areas instead, benefits from constructing 'environmentallyfriendly' wind farms - an alternative program which is also considered by the government - are not statistically different with respect to consumers' welfare to those associated with creating a new marine protected area. Methodologically, the paper makes a contribution by showing the ability of the latent class mixed logit model to represent both within-and between-class preference heterogeneity, and thus its power to provide a more sophisticated representation of preference heterogeneity than stand-alone latent class or mixed logit approaches. The paper is also presents the first use of the latent class mixed logit model in willingness-to-pay space for environmental goods.
\end{abstract}

Keywords: discrete choice experiment, off-shore wind energy, marine protected areas, willingness to pay space, latent class mixed logit, renewable energy.

JEL classification: Q51, O13, Q56, Q58, Q42, Q48, Q25, Q28

\footnotetext{
${ }^{1}$ Stockholm Environmental Institute, Tallinn, Estonia

* Corresponding author, aljona.karloseva@seit.ee

${ }^{2}$ University of Warsaw, Department of Economics, Poland

${ }^{3}$ University of St Andrews, School of Geography and Sustainable Development, UK
} 


\section{Highlights:}

- We analyse the trade-offs between wind energy production and the designation of marine protected areas in Estonia.

- Discrete choice modelling is used to estimate the relative welfare effects of 3 design options in two locations.

- A methodological enhancement to choice modelling is introduced, namely the latent class mixed logit model in willingness to pay space.

- The model shows distinct preference heterogeneity both within and between latent classes of respondents.

- On average, people prefer "eco" windfarms to conventional windfarms or marine protected areas.

Acknowledgments: This study was carried out as a part of the GES-REG project (Good Environmental Status through REGional coordination and capacity building), funded by Central Baltic INTERREG IV A Programme 2007-2013, co-funded by Enviromenatal Investment Center of Estonia. MC gratefully acknowledges the support of the Polish Ministry of Science and Higher Education and the Foundation for Polish Science. NH thanks MASTS (www.masts.ac.uk) for funding part of his work. 


\section{Introduction}

European climate and energy policies require both the reduction of member states' emissions of $\mathrm{CO} 2$ and an increase in the share of renewables in their energy mix (Böhringer, Rutherford and Tol, 2009). One of the means of moving towards the achievement of such targets is through utilizing wind energy, especially in countries with relatively lower solar or hydro energy potential. Because wind turbines require space and are often contested by local inhabitants due to noise and visual dis-amenity (Meyerhoff, Ohl and Hartje, 2010), there is a growing interest in locating new windfarms off-shore, away from inhabited areas. Previous economic valuation studies show both support for and opposition towards off-shore renewable installations (Ladenburg, 2010; Krueger, Parsons and Firestone, 2011). Such preferences for and against particular renewable technologies and locations for such technologies (Bergmann, Colombo and Hanley, 2008) needs to be seen in the context of a general overall support for the development of renewable energy sources, and wind power in particular, by the general public (Kosenius and Ollikainen, 2013).

Any new investment in off-shore wind energy is thus likely to give rise to both economic benefits (for those who support the expansion of renewables in this way, along with the value of electricity produced and the savings in $\mathrm{CO} 2$ and other pollutant emissions), and economic costs to those who oppose specific investments. The balance of benefits and costs is likely to be highly case-specific. However, a further complication arises from the potential choice between designating an area of the sea for renewable energy investments relative to designating the same area as a Marine Protected Area which could exclude such investments. MPAs are now seen as an important tool of ecosystem-based marine spatial management that can be employed to maintain marine ecosystems in a healthy, productive and resilient condition by balancing the increasing diversity and intensity of human activities with the sea's ability to provide ecosystem services (Olsen et al., 2013). A number of empirical studies report respondents' positive willingness to pay (WTP) for establishing marine protected areas (MPA), typically with preferences for more stringent restrictions on allowed uses of these areas (Wallmo and Edwards, 2008; Gillespie and Bennett, 2010; Wattage et al., 2011; Aanesen et al., 2015). EU law does not compel the use of cost-benefit approaches in the designation of MPAs, but economists would argue that such evidence is a useful input to the policy process (Hanley et al., 2015).

In the case of marine shoals (sand banks and reefs), wind farms and marine areas protection are competing uses of these scarce resources. On the one hand, such sites provide a good opportunity for installing wind turbines. On the other, they are ecologically valuable, providing rich spawning areas for fish and good habitat for birds and sea mammals. Siting wind farms in such areas can damage their ecological quality.

In this study we apply stated preference methods to investigate the general public's preferences for developing Estonian shoals into marine protected areas, wind farms, or "eco wind farms" (wind farms which are built with increased care for the environment and which include environmentally-friendly characteristics: Westerberg, Jacobsen and Lifran, 2013). The installation of off-shore wind farms would contribute to 
Estonia's energy security and potentially reduce the environmental impacts caused in particular by the use of oil shale for energy production. However, the installation of off-shore wind farms could cause negative impacts on the marine environment, although knowledge about these impacts is currently limited (see, for example, the limited literature on the effects of wind farm construction on sea birds: Furness, Wade and Masden, 2013). ${ }^{4}$

In this paper we provide evidence about how the general public is impacted in welfare terms by alternative uses (renewable energy and biodiversity conservation) of these marine areas. Results from a choice modelling exercise are used to estimate the benefits of alternative scenarios for the development or protection of a specific coastal area in Estonia. The paper is organized as follows. In Section 2 we describe the study location as well as the design and implementation of the survey. Section 3 introduces the econometric approach used, namely the latent class mixed logit model. We present the results in Section 4, including the estimated welfare changes resulting from implementing a particular policy. Section 5 summarizes and concludes.

\section{Empirical study}

\subsection{The study site}

Our empirical investigation concerns shallow marine areas north-west of Hiiumaa island in Estonia (Figure 1). Hiiumaa is Estonia's second-largest island, situated in the western section of the Estonian archipelago, and the shoals are situated 15-25 kilometers north of the island. These shoals are ecologically valuable because of the reef and sandbank habitats present. Both reef and sandbanks habitats are represented on both of the shoals, but there are relatively more sandbank habitats on the Apollo shoal (8\% of the area of the shoal) and relatively more reef habitats on the Western shoal (30\% of the area of the shoals). Reef habitats are relatively rare in the Baltic and they are biodiversity hot spots. The most important shoal from a seabird perspective is the Apollo. It provides a habitat for many bird species, including the long-tailed duck. The long-tailed duck is the most numerous wintering water bird in Estonia. However, their numbers have been in decline (for example, from 1993 to 2007 numbers of long-tailed duck in Baltic Sea region decreased by 65\%). For this reason, it has been proposed to manage the Apollo shoal differently from the other shoals.

\footnotetext{
${ }^{4}$ Research shows mixed impacts on marine mammals from off-shore wind turbines. Noise pollution from the construction process is likely to have negative effects on seals and cetaceans; but once constructed, wind turbines provide a habitat enhancement through the creation of artificial reefs. No-fishing regulations around windfarms can also benefit marine mammals.
} 
Figure 1. Planned locations of off-shore wind energy farms or new marine protected areas on Hiiumaa shoals (marked yellow)

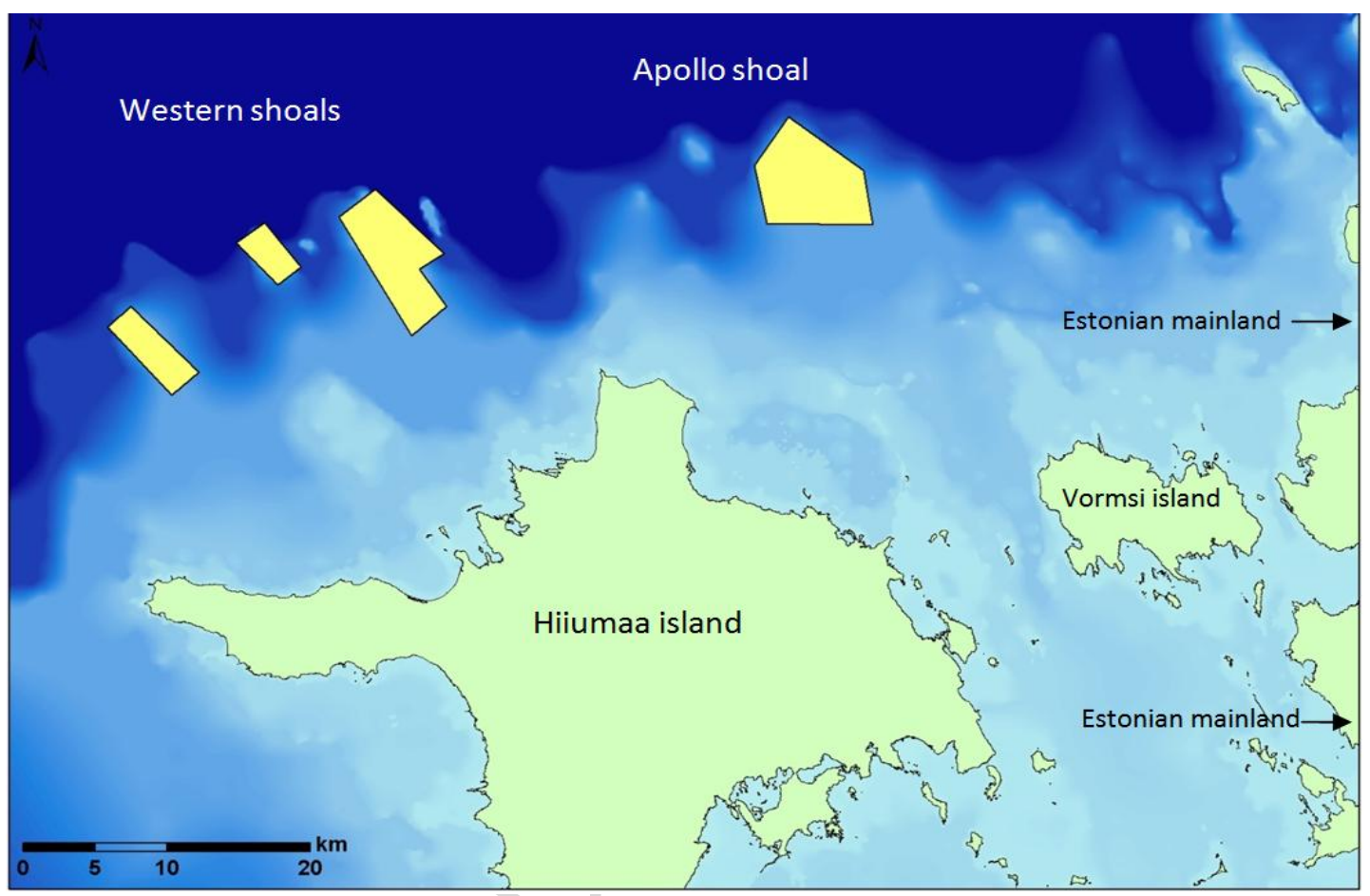

Our respondents were acquainted with the location and environmental significance of the shoals and informed, that although they are currently to a large extent undisturbed, a wind energy developer is planning to construct wind energy farms there. In total, approximately 200 wind turbines could be erected across the shoals. This investment would increase Estonian energy security - the annual electricity production there could reach as much as $22 \%$ of Estonian total electricity production, based on 2011 data. Respondents were also informed that constructing new wind farms could also have environmental benefits: even though Estonia has already reached the EU target of $20 \%$ of energy coming from renewable sources by 2020 , the main source of energy is still oil shale which is the source of several environmental problems such as the necessity to store dangerous waste, emissions of conventional pollutants and greenhouse gases emissions, pollution of water, and the decline of ground water levels during oil shale extraction.

Increasing the share of renewable energy sources in the national energy mix could help with these problems. On the other hand, construction of the wind farm would cause temporary but major pressures on the marine environment of Hiiumaa shoals. This means that bottom habitats would be strongly affected during construction; marine mammals, fish and birds would all be disturbed. During the operation phase, the impact on marine life is unclear. However, use of the shoals by birds in the event of significant wind turbine construction would probably be limited. 
In response to these plans for wind farm construction it has been proposed to establish marine protected areas on the Apollo shoal. Currently about $27 \%$ of marine waters in Estonia are under some form of regulated use (i.e. no fishing, mining or installation of wind turbines is allowed). If the shoals were designated as marine protected areas, this would allow marine mammals, birds and fish to thrive in these areas and would conserve their habitats. Finally, some of the development plans include the option of building an "eco wind farm" essentially a wind farm which would strive to minimize environmental pressures. The wind turbines would be located in areas where valuable bottom habitats are not present. The number of wind turbines would decrease while the power capacity of each turbine would increase, allowing the production of the same amount of electricity with reduced impacts on birds. The producer would also have to use the best available techniques in order to minimize the effects on the environment both during construction and operation phase. ${ }^{5}$ This "environmentally-friendly" windfarm development is used as a third option alongside the setting up of a new marine protected area and the construction of a conventional and thus less-environmentally-friendly offshore windfarm in the stated preference exercise reported below.

\subsection{Experimental design}

Stated preference methods are now widely used as a method to estimate the economic benefits and costs associated with environmental change (Hanley and Barbier, 2009). One of the more common stated preference methods is known as contingent valuation, where respondents are asked to state their maximum willingness to pay for an environmental improvement, or maximum willingness to pay to avoid an environmental degradation. In the contingent valuation study reported below, we utilized the discrete choice experiment method (Carson and Czajkowski, 2014) to elicit peoples' preferences and their willingness to pay for the support of different development options of the shoals. The development options under consideration for the Apollo and Western Shoals included a 'status quo' (no change over present) alternative, a marine protected area (MPA), a new off-shore windfarm (WF) as well as the eco windfarm option (ECO-WF). Table 1 provides a summary of the attributes and attributes levels used in the design.

\footnotetext{
${ }^{5}$ The survey included rather general descriptions of the differences between regular and eco wind farms. They were not substantiated with quantitative estimates and hence preferences for eco-wind farms could also be interpreted as e.g., preferences for using the best available technology.
} 
Table 1. Attributes and attribute levels used in the discrete choice experiment

\begin{tabular}{cll}
\hline \multicolumn{1}{c}{ Attribute } & \multicolumn{1}{c}{ Attribute level } & \multicolumn{1}{c}{ Description } \\
\hline \multirow{4}{*}{ Apollo shoal } & $A-S Q$ & No change, status quo is maintained (reference level) \\
& $A-M P A$ & Establishing a marine protected area \\
& $A-W F$ & Developing a wind farm \\
& $A-E C O-W F$ & Developing an 'environmentally friendly' wind farm \\
\hline \multirow{4}{*}{ Western shoals } & $W-S Q$ & Status quo is maintained (reference level) \\
& $W-M P A$ & Establishing a marine protected area \\
& $W-W F$ & Developing a wind farm \\
Cost & $W-E C O-W F$ & Developing an 'environmentally friendly' wind farm \\
\hline
\end{tabular}

Participants of the survey were provided with information about current economic uses and the ecological importance of the shoals. After they were familiarized with the current situation, we asked them to participate in a discrete choice experiment which elicited their preferences for each of the development options. The choice tasks included the status quo (no change) and two other alternatives, representing potential development scenarios with an associated cost. Each respondent was presented with 12 choice tasks. The experimental design was generated to minimize the D-error of the multinomial logit (MNL) model (Scarpa and Rose, 2008), using Bayesian priors (Bliemer, Rose and Hess, 2008) obtained in a pilot study (administered to 100 respondents) and updated after collecting the next 200 responses. $^{6}$ An example of a choice card is provided in Figure 2. The survey was developed in 2012-2013 in close cooperation with marine scientists, environmental organisations and the off-shore wind energy developer. The survey went through a thorough pretesting process, including the use of verbal "think-out-loud" protocols, consultations with stakeholders and a pilot study administered to a random sample of 100 respondents. The questionnaire was available in Estonian or Russian.

\footnotetext{
${ }^{6}$ All the designs included the parameter of the alternative specific constant in the efficiency measures and they incorporated a constraint that each of the non-SQ alternatives must involve a new development policy for the Apollo Shoal or/and the Western Shoals. The first of the designs (used for 100 respondents in the pilot study) was D-efficient with fixed 0 priors. The updated designs, administered to the subsequent 200 and 500 respondents, used Bayesian, normally distributed priors with means derived from the MNL models estimated on the samples available at the time and arbitrarily selected standard deviations, usually between $20-50 \%$ of the estimates (with some absolute minimum for the priors very close to zero). The Bayesian efficient designs were simulated with 10,000 Halton draws and used median Derror as the optimization criterion.
} 
Figure 2. An example of a choice card (translation)

Please choose the alternative which is the most preferable for you:

\begin{tabular}{|c|c|c|c|}
\hline & Status Quo & Alternative A & Alternative B \\
\hline Apollo shoal & No change & ECO-WF & MPA \\
\hline Western shoals & No change & WF & No change \\
\hline Cost to your household (EUR per year) & 0 & 10 & 5 \\
\hline YOUR CHOICE & & $\square$ & $\square$ \\
\hline
\end{tabular}

\subsection{Data collection}

The main data collection took place in August 2013. The survey was administered using computer-assisted web interviews to a representative sample of 800 adult citizens of Estonia. ${ }^{7}$ The overall sample was quotacontrolled for gender, age, nationality and place of residence. Table 2 presents the comparison of the characteristics between the sample and the target population and illustrates that the sample can be considered representative. $^{8}$

\footnotetext{
${ }^{7}$ Since there were no changes needed in the contingent scenario, descriptions or attributes and their levels for the main survey, the observations from 100 respondents obtained in the pilot were included in the main survey dataset which was used for analysis.

${ }^{8}$ We followed the recommendations of ICC/ESOMAR provided in the International Code on Market and Social Research (ESOMAR, 2008), which say that internet interviews are acceptable when the use of internet in the general population exceeds $60 \%$. This indicator for Estonia was close to $80 \%$ in December 2013, and is one of the highest in Europe (average 76.5\%). The recent metaanalyses (e.g., Menegaki, Olsen and Tsagarakis, 2015) allow us to be fairly optimistic that the difference between online and in-person surveys should be small (Lindhjem and Navrud, 2011; Liebe et al., 2015; Menegaki, Olsen and Tsagarakis, 2015).
} 
Table 2. A comparison of sample and target population characteristics

\begin{tabular}{lcc}
\hline & Sample & $\begin{array}{c}\text { Target } \\
\text { population }\end{array}$ \\
\hline Male & $46.0 \%$ & $46.4 \%$ \\
Age 15-34 & $34.0 \%$ & $34.2 \%$ \\
Age 35-49 & $27.0 \%$ & $26.8 \%$ \\
Age 50-74 & $39.0 \%$ & $39.0 \%$ \\
Nationality - Estonian & $67.4 \%$ & $68.3 \%$ \\
Nationality - non-Estonian & $32.6 \%$ & $31.7 \%$ \\
Residence - North Estonia & $43.0 \%$ & $43.2 \%$ \\
Residence - West Estonia & $11.0 \%$ & $11.2 \%$ \\
Residence - Central Estonia & $10.0 \%$ & $9.6 \%$ \\
Residence - North-East Estonia & $11.0 \%$ & $11.4 \%$ \\
Residence - South Estonia & $25.0 \%$ & $24.6 \%$ \\
Total & 800 & 1300000 \\
& respondents & citizens \\
\hline
\end{tabular}

\section{Econometric approach}

In what follows we infer respondents' preferences from the choices they made in the choice experiment. Theoretical foundations for quantitative modelling of consumers' utility functions are provided by random utility theory (McFadden, 1974). Simple applications of this approach (e.g., the multinomial logit model) assume all individuals have the same preferences. More elaborate methods allow for unobserved preference heterogeneity in the form of membership in latent classes of preferences (the latent class multinomial logit model), or else allow parameters of respondents' utility functions to be random and to follow particular parametric distributions (the mixed logit model). We combine these two approaches by allowing the population's utility function parameters to come from latent groups of random parameters, known as a Latent Class Mixed Logit (LCMXL) model.

The LCMXL allows for both segmentation of respondents into classes with similar preferences, and unobserved preference heterogeneity within these classes, the latter introduced via random parameters. The model is relatively new and so far has rarely been used. It allows for highly flexible, possibly multi-modal distributions of respondents' preferences. It permits more flexibility in representing preference heterogeneity than the standard latent class model or the mixed logit model. Greene and Hensher (2012) apply LCMXL to analyze preferences for freight distribution trips and Xiong and Mannering (2013) use it to investigate the influence of guardian supervising on adolescent drivers' car crashes. Hess et al. (2013), Yoo and Ready (2014), and Campbell, Hensher and Scarpa (2014) use the LCMXL model to investigate attribute nonattendance by constraining parameters associated with specific attributes to zero in some of the latent classes. 
Formally, in the LCMXL model individual $i$ 's utility resulting from choosing the alternative $j$ at choice occasion $t$, conditional on individual $i$ belonging to class $c$ out of $C$ classes can be expressed as:

$$
V_{i j t}^{c}=a_{i}^{c} p_{i j t}+\mathbf{b}_{i}^{c^{\prime}} \mathbf{X}_{i j t}+e_{i j t}^{c},
$$

where the utility expression is separable in price, $p_{i j t}$, and other non-price attributes, $\mathbf{X}_{i j t}, a$ and $\mathbf{b}$ are the associated parameters and $e_{i j t}^{c}$ is a stochastic component allowing for other factors than those observed by an econometrician to affect individuals' utility and choices.

Two things in the above specification need to be noted. First of all, $a_{i}^{c}$ and $\mathbf{b}_{i}^{c}$ are individual-specific, thus the index $c$ seems to be irrelevant as every respondent belongs to only one class. However, the researcher does not know to which class each individual belongs, so a probabilistic framework is applied which assumes that every respondent belongs to every class with some probability which has to be estimated. These probabilities describe between-class heterogeneity, while $a_{i}^{c}$ and $\mathbf{b}_{i}^{c}$ represent within- class heterogeneity. ${ }^{9}$ Secondly, the stochastic component of the utility function $\left(e_{i j t}^{c}\right)$ is of unknown, and possibly of heteroskedastic variance $\left(\operatorname{var}\left(e_{i j t}^{c}\right)=\left(s_{i}^{c}\right)^{2}\right)$, which can also differ between classes for a given individual. Identification of the model is typically assured by normalizing this variance, such that the error term $\varepsilon_{i j t}^{c}=e_{i j t}^{c} \pi /\left(\sqrt{6} s_{i}^{c}\right)$ is identically and independently extreme value type one distributed (with constant variance $\operatorname{var}\left(\varepsilon_{i j t}^{c}\right)=\pi^{2} / 6$ ), leading to the following specification:

$$
U_{i j t}^{c}=\sigma_{i}^{c} a_{i}^{c} p_{i j t}+\sigma_{i}^{c} \mathbf{b}_{i}^{c^{\prime}} \mathbf{X}_{i j t}+\varepsilon_{i j t}^{c} .
$$

Note that due to the ordinal nature of utility, this specification still represents the same preferences as in (1). The estimates $\sigma_{i}^{c} a_{i}^{c}$ and $\sigma_{i}^{c} \boldsymbol{b}_{i}^{c}$ do not have direct interpretation anyway, but if interpreted in relation to each other the scale coefficient $\left(\sigma_{i}^{c}=\pi /\left(\sqrt{6} s_{i}^{c}\right)\right.$ ) cancels out.

Finally, given the interest in establishing estimates of WTP for the non-monetary attributes $\boldsymbol{X}_{n j t}$, it is convenient to introduce the following modification which is equivalent to using a money-metric utility function:

\footnotetext{
${ }^{9}$ It is typically assumed that individual parameters in each class follow particular parametric distributions (possibly multivariate distribution, allowing for non-zero correlations of model parameters). Assuming that the parameters are the same for all respondents in a class leads to the basic latent class multinomial logit model (LCMNL).
} 


$$
U_{i j t}^{c}=\sigma_{i}^{c} a_{i}^{c}\left(p_{i j t}+\frac{\mathbf{b}_{i}^{c^{\prime}}}{a_{i}^{c}} \mathbf{X}_{i j t}\right)+\varepsilon_{i j t}^{c}=\sigma_{i}^{c} a_{i}^{c}\left(p_{i j t}+\boldsymbol{\beta}_{i}^{c^{\prime}} \mathbf{X}_{i j t}\right)+\varepsilon_{i j t}^{c} .
$$

Note that under this specification (which is similar to WTP-space mixed logit: Train and Weeks, 2005), the vector of parameters $\boldsymbol{\beta}_{i}^{c}$ is now (1) scale-free so that (3) can be directly interpreted as a vector of implicit prices for the attributes $\boldsymbol{X}_{i j t}$. An additional advantage of this specification is that the econometrician is able to specify a particular distribution of WTP in a given class (by specifying the distribution of $\boldsymbol{\beta}_{i}^{c}$ ) rather than the distribution of the underlying taste parameters $\left(\boldsymbol{b}_{i}^{c}\right)$.

An individual chooses alternative $j$ if $U_{i j t}^{c}>U_{i k t}^{c}$, for all $k \neq j$, and therefore the probability of respondent's choices conditional of his membership in class $c$ is given by:

$$
P\left(y_{i} \mid \mathbf{X}_{i}, \boldsymbol{\Omega}^{c}, \text { class }=c\right)=\int \prod_{t=1}^{T_{i}} \frac{\exp \left(\sigma_{i}^{c} a_{i}^{c}\left(p_{i j t}+\boldsymbol{\beta}_{i}^{c^{\prime}} \mathbf{X}_{i j t}\right)\right)}{\sum_{k=1}^{c} \exp \left(\sigma_{i}^{c} a_{i}^{c}\left(p_{i k t}+\boldsymbol{\beta}_{i}^{c^{\prime}} \mathbf{X}_{i k t}\right)\right)} d\left(a_{i}^{c}, \boldsymbol{\beta}_{i}^{c}\right),
$$

where $\boldsymbol{\Omega}^{c}$ contains all parameters which define $\boldsymbol{\beta}_{i}^{c}$ and $a_{i}^{c}$ distributions. The $\boldsymbol{\beta}_{i}^{c}$ and $a_{i}^{c}$ are not directly observed in data, so they have to be integrated out to obtain an unconditional probability. The probability of respondent $i$ being a member of class $c$ is given by the logit formula ${ }^{10}$ :

$$
\pi_{c}=\frac{\exp \left(\boldsymbol{\theta}_{c}^{\prime} \mathbf{Z}_{\mathbf{i}}\right)}{1+\sum_{k=1}^{C-1} \exp \left(\boldsymbol{\theta}_{k}^{\prime} \mathbf{Z}_{\mathbf{i}}\right)}
$$

where $\mathbf{Z}_{\mathbf{i}}$ is a vector containing a constant and possibly other explanatory variables of class membership, such as respondents' socio-demographic characteristics. This leads, finally, to the following formula for the probability of observing individual $i$ 's choices $y_{i}$ :

$$
P\left(y_{i} \mid \mathbf{X}_{i}, \mathbf{Z}_{\mathbf{i}}, \mathbf{\Omega}\right)=\sum_{c=1}^{c} \pi_{c} P\left(y_{i} \mid \mathbf{X}_{i}, \mathbf{\Omega}^{c}, \text { class }=c\right),
$$

where $\boldsymbol{\Omega}$ contains all parameters associated with $\boldsymbol{\Omega}^{c}$ and $\boldsymbol{\theta}_{c}$.

${ }^{10}$ For $c=1, \ldots, C-1 . \pi_{C}$ is defined so that $\sum_{c=1}^{C} \pi_{c}=1$. 
The model can be estimated using the maximum likelihood method. Since there is no closed form solution to the multiple integral provided in (4), simulation-based optimization methods must be used.

\section{Results}

We now apply the model described in the previous section to the discrete choice data collected in our empirical study in order to gain an insight into respondents' preferences and whether we are able to identify distinct groups of respondents who are similar with respect to their preferences. Overall, this exercise provides an overview of the social preferences for marine protected areas compared to wind farms, using the Estonian shoals as the case study.

Table 3 presents the estimation results of the LCMXL model ${ }^{11,12}$ - the estimates of utility function coefficients (means and standard deviations of normally distributed ${ }^{13}$ parameters) are shown for each of the three latent classes of preferences. ${ }^{14}$ Since the model was estimated in WTP-space, the coefficients can be interpreted as the respondents' marginal willingness to pay for the program attributes. Overall, the model exhibits a very good fit to the data. We found that this specification outperformed other models, such as the latent class model with non-random parameters and the mixed logit model with or without correlations, showing that the LCMXL specification provides a useful tool when distribution of respondents' preferences in the population is highly heterogeneous and possibly multi-modal.

The three latent preference classes we were able to identify can be conveniently interpreted with respect to what kind of policies respondents appreciate the most. The first major difference between the classes is the

11 The model was estimated using custom code in Matlab. Translation of the original questionnaire, dataset and software codes are available online at czaj.org.

12 The maximum likelihood function was simulated using 10,000 Sobol draws (Czajkowski and Budziński, 2015). As an aside, we found that using more draws for the simulation facilitated identification of the global maximum of the loglikelihood function more efficiently than using multiple starting points with only a few hundred draws (cf. Campbell, Hensher and Scarpa, 2014).

${ }^{13}$ All WTP-space attribute coefficients were assumed to be random and normally distributed, with the exception of the coefficient representing the product of the scale and marginal utility of income (COST), which was assumed to follow lognormal distribution to constrain its sign. For the lognormally distributed coefficient, the estimated mean and standard deviation of the underlying normal distribution is reported. The cost enters the model with a negative sign and was scaled by a factor of 10 to facilitate convergence.

${ }^{14}$ The model with 3 classes outperformed the model with 2 classes in terms of lower Akaike Information Criterion index and as confirmed with the Vuong test result. We also tried models with 4 or more classes, however, we found that they did not provide stable results and/or exhibited convergence problems (e.g., numerical problems, problems with inverting the estimate of the Hessian, extreme standard errors). We did not find this particularly surprising - the LL function of the LCMXL model in WTP-space is not necessarily globally concave and generally difficult to optimize; in our case, this resulted in the models with more than 3 classes leading to estimation/identification problems. 
perception of the status quo $(S Q)$. Respondents with class 1 preferences are generally indifferent (since the mean of the $S Q$ parameter is not significantly different from zero), class 2 respondents are dissatisfied with the $S Q$ (they have a negative marginal WTP of 6.65 EUR associated with choosing this option), whilst class 3 respondents are happy with it (they would be WTP 11.26 EUR per year to retain the status quo). It is worth noting that there is a high variation with respect to how satisfied / dissatisfied with the current management policy respondents are, as shown by high standard deviations of the $S Q$ with respect to their means.

With regard to willingness to pay for establishing marine protected areas, Class 1 respondents are the most keen on this change (shown by a WTP of 29.88 and 32.83 EUR for the Apollo and Western Shoals, respectively). Their next-preferred option is an 'eco' wind farm on Apollo Shoal (13.94 EUR) and a conventional wind farm on the Western shoals (26.19 EUR). In contrast, Class 2 respondents are generally against establishing wind farms on any of the shoals (-73.00 and -39.10 EUR for Apollo and Western Shoals, respectively) but they would be in favor, on average, of establishing 'eco' wind farm on Apollo Shoal (WTP of 7.13 EUR), indifferent with respect to establishing 'eco' wind farms on Western Shoals, and they do not approve of establishing a marine protected area in the Apollo shoals (WTP of -17.79 EUR). Class 3 respondents are generally indifferent with respect to any development options - they seem to be satisfied with the status quo and appear the most concerned about the costs of the programs. 
Table 3. The results of the latent class mixed logit (LCMXL) model used to investigate preferences for developing Estonian shoals into marine protected areas or wind farms; the model was estimated in WTP-space - coefficients can be interpreted as marginal WTPs in EUR

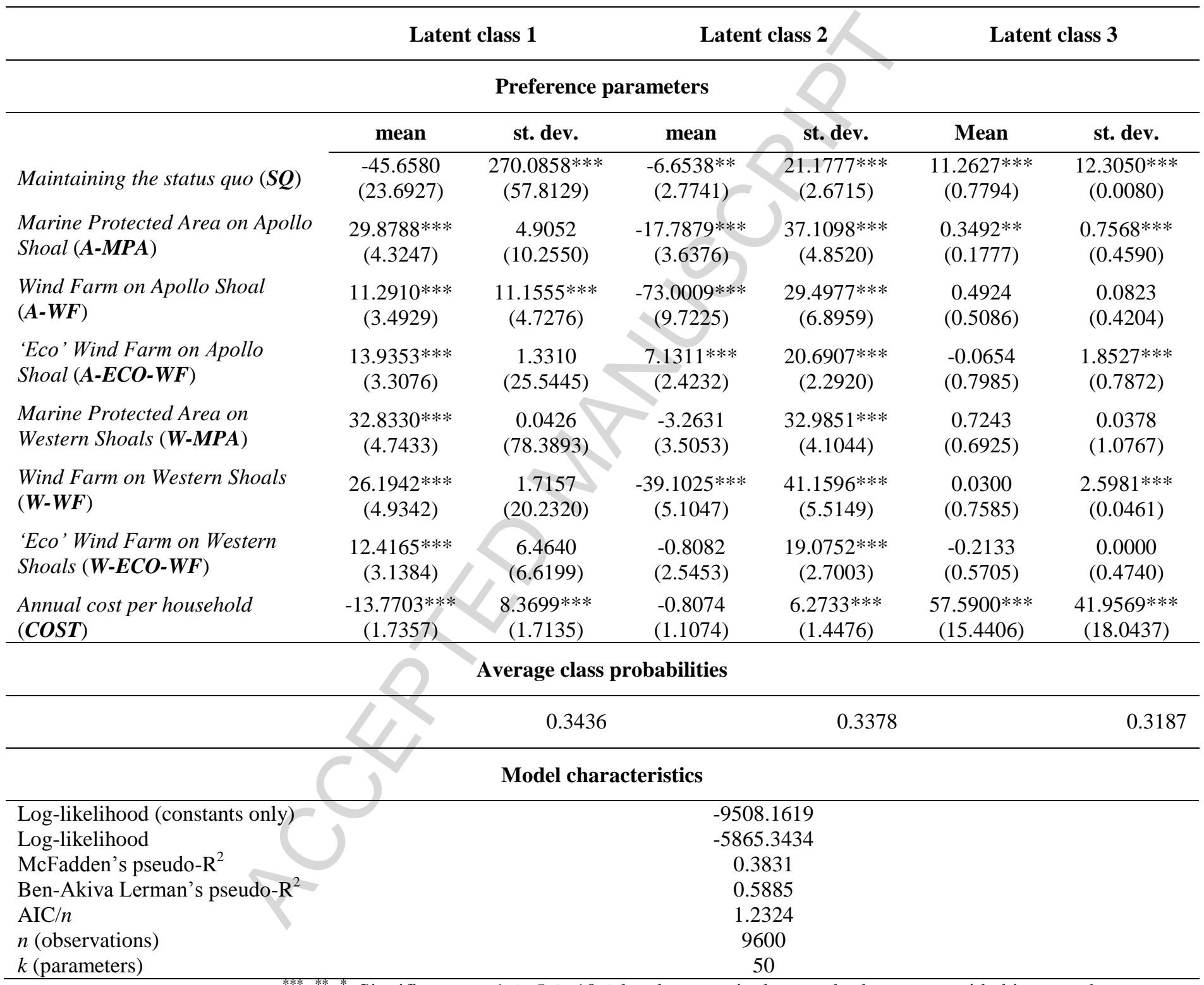

,${ }^{*}$ Significance at $1 \%, 5 \%, 10 \%$ level, respectively; standard errors provided in parentheses

The results described in the preceding paragraph concern the means of the distributions of WTP for each of the attribute in each class. It is worth noting, however, that there is also significant and relatively large preference heterogeneity within each class with respect to how the attributes are viewed. ${ }^{15}$ This can be seen by

\footnotetext{
${ }^{15}$ As noted by one of our reviewers, this could also be an indication that a model with more latent classes could capture some of this unobserved heterogeneity, leading to the estimates of standard deviations of some parameters becoming smaller or even not significantly different from zero. Unfortunately, we were not able to obtain stable and reliable results
} 
consulting the standard deviation column of parameters for each latent class. Furthermore, each respondent's preferences are represented with a class membership probability-weighted set of preferences for each of the three classes. To illustrate the extent of preference heterogeneity our model allows for, and the possible multimodality of the distributions of individual-specific (posterior) WTP-space parameters we calculated these estimates for each of the choice attributes. ${ }^{16}$ The kernel densities of the marginal WTP distributions are provided in Figure 3. These results demonstrate that the model indeed allows for a very large extent of preference heterogeneity, and possibly multi-modal distributions of posterior estimates of individual-specific preference parameters (WTPs). Interestingly, the results also show that for most attributes, there are conflicting views. There are groups of respondents who value them positively, as well as groups who would not want to see a policy implemented.

Finally, in order to provide clearer policy recommendations, we simulated the aggregate non-market net benefits associated with three policy options:

(1) converting all the shoals into marine protected area;

(2) establishing conventional wind farms in each location; and

(3) establishing 'eco' wind farms in each location.

To do this, we took $10^{7}$ draws from the multivariate normal distribution described by the coefficients estimated and their associated variance-covariance matrix. For each set of parameters (i.e., each draw) we calculated the welfare measures associated with the policy options. The results are presented in Table 4. The results show that developing the Estonian Shoals into Marine Protected Areas would provide the highest nonmarket benefits of on average 29.13 EUR per year per household but this would not be statistically different from establishing 'Eco' Wind Farms there (annual benefits per household 25.45 EUR). These two policies would constitute an improvement with respect to the status quo, while converting the shoals into conventional wind farms can be associated with an annual loss of 10.47 EUR per household.

We also note, however, that there is large imprecision surrounding these estimates. This is likely to be at least partly a result of the fact that the design of our DCE did not include bids higher than 20 EUR, and in fact the alternative with the highest bid (20 EUR) was selected in $16.71 \%$ of choice tasks in which it was one of the options. Despite this, we believe our results still provide interesting insights into public preferences for different management options of marine shoals in Estonia.

for the model with more than 3 latent classes.

${ }^{16}$ This is possible by combining the information about the overall distribution of preferences in the population with the knowledge of each respondent's choices using Bayes' formula. 
Table 4. Simulated welfare change associated with implementing a uniform policy (Marine Protected Area, Conventional Wind Farm, or 'Eco' Wind Farm) on all of the shoals (values are EURO per year per household)

\begin{tabular}{cccc}
\hline & $\begin{array}{c}\text { Marine Protected } \\
\text { Areas }\end{array}$ & $\begin{array}{c}\text { Conventional Wind } \\
\text { Farms }\end{array}$ & ECO-Wind Farms \\
Mean & 29.13 & -10.47 & 25.46 \\
(st.error) & $(8.9458)$ & $(9.8009)$ & $(8.0011)$ \\
$95 \%$ c.i. & $(11.60 ; 46.71)$ & $(-29.65 ; 8.79)$ & $(9.77 ; 41.13)$ \\
\hline
\end{tabular}


ACCEPTED MANUSCRIPT

Figure 3. Kernel smoothing density function plots representing the distribution of individual-specific (posterior) preferences (mean WTP) for the policy attributes
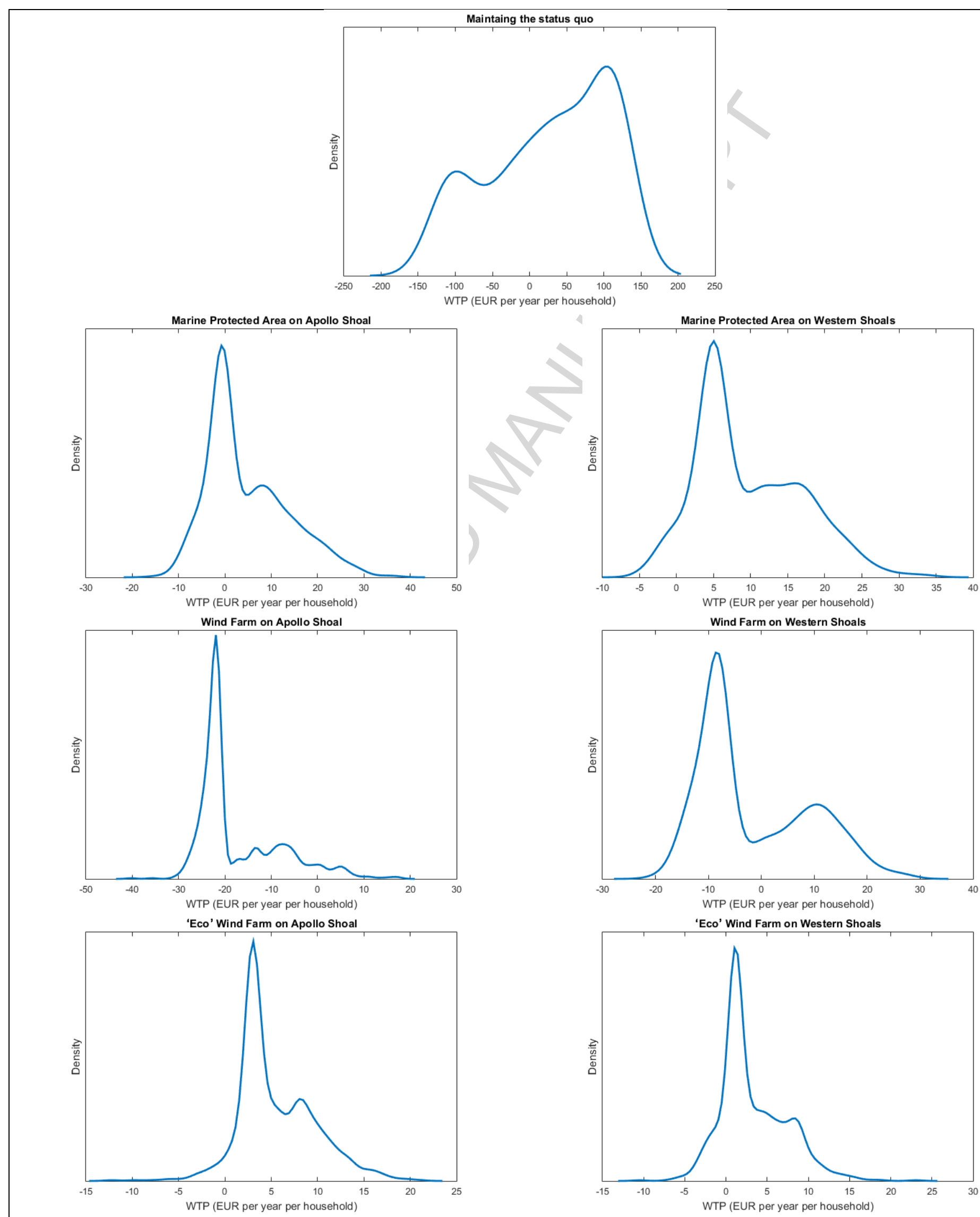

17 


\section{Summary and Conclusions}

Many countries world-wide have set targets for expanding the fraction of electricity generated from renewable energy, and cutting greenhouse gas emissions. Investing in wind power has been a major element of the increase in renewable energy capacity in Europe, but the siting of new wind farms creates economic costs in terms of dis-amenity and effects on wildlife. The move to site new wind capacity off-shore changes and shifts these land-based externalities spatially, but does not avoid them. Moreover, such investments create trade-off situations where governments must evaluate the relative environmental and economic benefits and costs of new off-shore wind farms against other policy options such as the creation of marine protected areas.

In this paper, we use choice modelling to investigate the relative gains and losses from siting new windfarms off the coast of Estonia, relative to the option of creating a new marine protected area. The focus is on marine shoals which are high biodiversity locations, but also locations of high potential for wind energy. A finding which emerges is that citizens are willing to pay both for "environmentallyfriendly" new windfarms and the designation of new marine protected areas. They would also be willing to pay to avoid the siting of conventional windfarms in these shoals. Considerable differences also emerge in the willingness to pay for each of these three options between the two areas within the case study site, namely the Apollo and Western Shoals, as may be seen by comparing the mean WTP estimates in Table 3 and the distributions of WTP values shown in Figure 3. There are also considerable differences in preferences towards retaining the status quo.

Since many governments incentivize new wind energy investments in a way which leads developers to prefer locations and designs which maximize private returns, it is unlikely that the market-driven investment outcome would be in accord with the ranking of options shown in Table 4 in terms of welfare change. Thus, the government would need to re-align incentives such as feed-in tariffs or green certificates, or add additional planning restrictions, for the "environmentally-friendly" option to be also that preferred by developers. Moreover, designation of marine protected areas comes at an economic cost to producers whose activities are thus restricted (e.g., energy firms, fisherman, oil and gas firms). Such costs would need to be weighed against the benefits to citizens from MPA creation in order to determine which action maximizes net social benefits over time. That is not a comparison we were able to make in this paper.

Methodologically, the paper makes a contribution by showing the ability of the latent class mixed logit model to represent both within-and between-class preference heterogeneity, and thus its power to provide a more sophisticated representation of preference heterogeneity than latent class or mixed logit approaches. The paper is also the first to use the latent class mixed logit in willingness-to-pay space for environmental goods. This is valuable since researchers have long argued that willingness- 
to-pay space models have several advantages over preference space models in the context of simpler mixed logit approaches. We find that the model works well. However, obtaining stable and reliable results for LCMXL models with more than 3 latent classes proved difficult in the case of our dataset. The presence of substantial unobserved heterogeneity within each class could be an indication that models with more latent classes could fit the data even better. 


\section{References}

Aanesen, M., Armstrong, C., Czajkowski, M., Falk-Petersen, J., Hanley, N., and Navrud, S., 2015. Willingness to pay for unfamiliar public goods: Preserving cold-water corals in Norway. Ecological Economics, 112:53-67.

Bergmann, A., Colombo, S., and Hanley, N., 2008. Rural versus urban preferences for renewable energy developments. Ecological Economics, 65(3):616-625.

Bliemer, M. C. J., Rose, J. M., and Hess, S., 2008. Approximation of Bayesian Efficiency in Experimental Choice Designs. Journal of Choice Modelling, 1(1):98-127.

Böhringer, C., Rutherford, T. F., and Tol, R. S. J., 2009. THE EU 20/20/2020 targets: An overview of the EMF22 assessment. Energy Economics, 31, Supplement 2(0):S268-S273.

Campbell, D., Hensher, D. A., and Scarpa, R., 2014. Bounding WTP distributions to reflect the 'actual' consideration set. Journal of Choice Modelling, 11(0):4-15.

Carson, R. T., and Czajkowski, M., 2014. The Discrete Choice Experiment Approach to Environmental Contingent Valuation. In: Handbook of choice modelling, S. Hess and A. Daly, eds., Edward Elgar, Northampton, MA.

Czajkowski, M., and Budziński, W. (2015). "An insight into the numerical simulation bias - a comparison of efficiency and performance of different types of quasi Monte Carlo simulation methods under a wide range of experimental conditions." In: Environmental Choice Modelling Conference, Copenhagen.

ESOMAR, 2008. ICC/ESOMAR International Code on Market and Social Research.

Furness, R. W., Wade, H. M., and Masden, E. A., 2013. Assessing vulnerability of marine bird populations to offshore wind farms. Journal of Environmental Management, 119(0):56-66.

Gillespie, R., and Bennett, J., 2010. Non Use Economic Values of Marine Protected Areas in the South-West Marine Region. Research Report 107582, Environmental Economics Research Hub, Australian National University.

Greene, W. H., and Hensher, D. A., 2012. Revealing additional dimensions of preference heterogeneity in a latent class mixed multinomial logit model. Applied Economics, 45(14):1897-1902.

Hanley, N., and Barbier, E. B., 2009. Pricing Nature. Cost-Benefit Analysis and Environmental Policy. Edward Elgar, Edward Elgar, Cheltenham, UK and Northampton, MA, USA.

Hanley, N., Hynes, S., Patterson, D., and Jobstvogt, N., 2015. Economic Valuation of Marine and Coastal Ecosystems: Is it currently fit for purpose? Journal of Ocean and Coastal Economics, 2:Article 1.

Hess, S., Stathopoulos, A., Campbell, D., O'Neill, V., and Caussade, S., 2013. It's not that I don't care, I just don't care very much: confounding between attribute non-attendance and taste heterogeneity. Transportation, 40(3):583-607.

Kosenius, A.-K., and Ollikainen, M., 2013. Valuation of environmental and societal trade-offs of renewable energy sources. Energy Policy, 62(0):1148-1156.

Krueger, A. D., Parsons, G. R., and Firestone, J., 2011. Valuing the Visual Disamenity of Offshore Wind Power Projects at Varying Distances from the Shore: An Application on the Delaware Shoreline. Land Economics, 87(2):268-283.

Ladenburg, J., 2010. Attitudes towards offshore wind farms - The role of beach visits on attitude and demographic and attitude relations. Energy Policy, 38(3):1297-1304.

Liebe, U., Glenk, K., Oehlmann, M., and Meyerhoff, J., 2015. Does the use of mobile devices (tablets and smartphones) affect survey quality and choice behaviour in web surveys? Journal of Choice Modelling, 14:17-31.

Lindhjem, H., and Navrud, S., 2011. Are Internet surveys an alternative to face-to-face interviews in contingent valuation? Ecological Economics, 70(9):1628-1637.

McFadden, D., 1974. Conditional Logit Analysis of Qualititative Choice Behaviour. In: Frontiers in Econometrics, P. Zarembka, ed., Academic Press, New York, NY, 105-142.

Menegaki, A. N., Olsen, S. B., and Tsagarakis, K. P. (2015). "Towards a common standard - A reporting checklist for web-based stated preference valuation surveys." In: Webdatanet Conference, Salamanca, Spain. 
Meyerhoff, J., Ohl, C., and Hartje, V., 2010. Landscape externalities from onshore wind power. Energy Policy, 38(1):82-92.

Olsen, E. M., Fonseca, L., Goñi, R., Johnson, D., Katsanevakis, S., Macpherson, E., (Chair), E. M. O., Pelletier, D., Rabaut, M., Ribeiro, M. C., Weaver, P., and Zaharia, T., 2013. Achieving Ecologically Coherent MPA Networks in Europe: Science Needs and Priorities. In: Marine Board Position Paper 18, K. Larkin, Maud Evrard, and A. Carbonnière, eds., European Marine Board, Ostend, Belgium.

Scarpa, R., and Rose, J. M., 2008. Design Efficiency for Non-Market Valuation with Choice Modelling: How to Measure it, What to Report and Why. Australian Journal of Agricultural and Resource Economics, 52(3):253-282.

Wallmo, K., and Edwards, S., 2008. Estimating Non-market Values of Marine Protected Areas: A Latent Class Modeling Approach. Marine Resource Economics, 23(3):301-323.

Wattage, P., Glenn, H., Mardle, S., Van Rensburg, T., Grehan, A., and Foley, N., 2011. Economic value of conserving deep-sea corals in Irish waters: A choice experiment study on marine protected areas. Fisheries Research, 107(1-3):59-67.

Westerberg, V., Jacobsen, J. B., and Lifran, R., 2013. The case for offshore wind farms, artificial reefs and sustainable tourism in the French mediterranean. Tourism Management, 34(0):172-183.

Xiong, Y., and Mannering, F. L., 2013. The heterogeneous effects of guardian supervision on adolescent driver-injury severities: A finite-mixture random-parameters approach. Transportation Research Part B: Methodological, 49(0):39-54.

Yoo, J., and Ready, R. C., 2014. Preference heterogeneity for renewable energy technology. Energy Economics, 42(0):101-114. 


\section{Marine trade-offs: comparing the benefits of off-shore wind farms and marine protected areas}

\section{Highlights:}

- We analyse the trade-offs between wind energy production and the designation of marine protected areas in Estonia.

- Discrete choice modelling is used to estimate the relative welfare effects of 3 design options in two locations.

- A methodological enhancement to choice modelling is introduced, namely the latent class mixed logit model in willingness to pay space.

- The model shows distinct preference heterogeneity both within and between latent classes of respondents.

- On average, people prefer "eco" windfarms to conventional windfarms or marine protected areas. 